\title{
Solid-Liquid Extraction Kinetics of Total Phenolic Compounds (TPC) from Red Dates
}

\author{
Chua Bee Lin ${ }^{1, *}$, and Chen Yen Leng ${ }^{1}$ \\ ${ }^{1}$ School of Engineering, Taylor's University, 47500 Subang Jaya, Selangor, Malaysia
}

\begin{abstract}
Red dates are one of the most famous herbal plants in making traditional Chinese medicine. They contain large amount of bioactive compounds. The objectives of this research were to optimise the crude extract yield and total phenolic compounds (TPC) yield from red dates using response surface methodology (RSM) and model the extraction kinetics of TPC yield from red dates. Date fruits were dried in an oven under temperatures $50^{\circ} \mathrm{C}, 60^{\circ} \mathrm{C}, 70^{\circ} \mathrm{C}$ and $80^{\circ} \mathrm{C}$ until a constant weight was obtained. The optimum drying temperature was $60^{\circ} \mathrm{C}$ as it gave the highest crude extract yield and TPC yield. Besides that, single factor experiments were used to determine the optimum range of four extraction parameters which were: liquid-solid ratio $(10-30 \mathrm{ml} / \mathrm{g})$; ultrasonic power (70-90\%); extraction temperature $\left(50-70^{\circ} \mathrm{C}\right)$; and extraction time $(40-$ $60 \mathrm{~min})$. The optimum range of the four parameters were further optimised using the Box-Behken Design (BBD) of RSM. The extraction conditions that gave the highest crude extract yield and TPC yield were chosen. The optimum value for liquid-solid ratio, ultrasonic power, extraction temperature and extraction time were $30 \mathrm{ml} / \mathrm{g}, 70 \%, 60^{\circ} \mathrm{C}$ and $60 \mathrm{~min}$ respectively. The two equations generated from RSM were reliable and can be used to predict the crude extract yield and TPC yield. The higher the extraction temperature, liquid-solid ratio, and extraction time and lower ultrasonic power, the higher the crude extract and TPC yield. Finally, the results of TPC yield versus time based on the optimum extraction parameters from RSM optimisation were fitted into three extraction kinetic models (Peleg's model, Page's model and Ponomaryov's model). It was found that the most suitable kinetic model to represent the extraction process of TPC from red dates was Page's model due to its coefficient of determination $\left(R^{2}\right)$ was the closest to unity, 0.9663 while its root mean square error (RMSE) was the closest to zero, 0.001534 .
\end{abstract}

\section{Introduction}

Medical plants have similar properties as pharmaceutical drugs. They can be used for medical purposes as they contain chemical compounds which help humans with their health

\footnotetext{
${ }^{1}$ Corresponding author: beelin.chua@taylors.edu.my
} 
and prevent diseases. There are 21,000 plants around the world can be used for medical purposes due to their high nutritional values according to World Health Organization [1].

Red dates are described as 'the king of nuts' [2]. They are one of the most famous and useful herbal plants in making traditional Chinese medicine. Red dates contain a high level of Vitamin C which can help improve insomnia, protect the liver and reduce cholesterol [3]. In addition, red dates also contain a large amount of total phenolic compounds (TPC) that increases their antioxidant activity by removing free radicals which cause cancer and other diseases [4].

For an accurate analysis, the optimisation of extraction process is needed. Response Surface Methodology (RSM) is a useful tool to optimise extraction process. It helps to lower the cost of the process and it gives better understanding of the extraction process [5]. RSM has been applied successfully for Macadamia tetraphylla and other herbal plants but no article is available regarding the optimisation of crude extract yield and TPC yield of red dates [6].

From an engineering perspective, it is very helpful to do a mathematical modeling of extraction processes. It is used to model the experiment, relate the consumption of energy, time, solvent and other parameters to the extraction kinetics [7]. The widely used extraction kinetic models of antioxidant compounds included Peleg's model, Page's model and Ponomaryoc's model. To find the best fitted model of the extraction process, the correlation coefficient $\left(R^{2}\right)$ and root mean square error (RMSE) were calculated. The closer the $R^{2}$ and RMSE to unity and zero respectively, the higher the fit of predicted kinetic models to the experimental data.

To the best of author's knowledge, the optimisation of crude extract yield, TPC yield from red dates was not widely developed. The reported findings regarding the antioxidant activity of TPC yield were inconsistent. There were also three commonly used models were not widely used to describe the process of extraction of TPC from red dates. They were Peleg's model, Page's model and Ponomaryov's model. 
One of the objectives of this research was to optimise the crude extract yield and TPC yield of red dates using response surface methodology (RSM). Box-Behnken Design (BBD) with three central points of RSM was used due to its high efficiency and less number of experiments were required thus lowering the total cost [8]. Another objective was to model the extraction kinetics of crude extract yield from red dates. Among the mentioned three kinetic models (Peleg's model, Page's model and Ponomaryov's model), the best fitted extraction kinetic model was chosen to predict the output of extraction process of TPC from red dates.

\section{Methodology}

The methodology conducted to achieve the objectives of this research was discussed in this section. Also, the analysis and justification of all tasks were included.

\subsection{Ultrasonic Extraction of Total Phenolic Compounds from Red Dates}

$50 \mathrm{~g}$ of date fruits with no seeds were washed with tap water and dried in an oven at 50,60, 70 and $80^{\circ} \mathrm{C}$ respectively until constant weight was obtained. The dried fruit was grinded to powder using blender. $11 \mathrm{~g}$ of red dates powder was extracted for $60 \mathrm{~min}$ with $165 \mathrm{ml}$ of pure ethanol as extraction solvent in an ultrasonic bath under $60^{\circ} \mathrm{C}$. The ultrasonic bath was operated at $70 \%$ of input power and $37 \mathrm{~kW}$. After $60 \mathrm{~min}$, the mixture was placed in a rotary evaporator under $40{ }^{\circ} \mathrm{C}$ until crude extract was observed. The crude extract was weighted to determine the crude extract yield.

\subsection{Quantification of Total Phenolic Compound Yield from Red Dates}

The quantification of TPC yield from red dates was carried out by using gallic acid as a standard [4]. $0.1 \mathrm{~g}$ of crude extract was dissolved in $1.5 \mathrm{ml}$ of distilled water. $5 \mathrm{ml}$ of $10 \%$ of Folin-Ciocalteu phenol reagent, $4 \mathrm{ml}$ of $7 \%$ of $\mathrm{Na}_{2} \mathrm{CO}_{3}$ and $1 \mathrm{ml}$ of extract were mixed together. After 1 hour, the mixture was poured into 96-well plate. The first row of the 96 well plate was filled with $0.2 \mathrm{ml}$ of pure ethanol to act as blank solution. The 96-well plate was then placed into microplate spectrophotometer to measure its absorbance at $765 \mathrm{~nm}$. The amount of gallic acid from red dates were determined by referring to the calibration curve of gallic acid plotted. Concentration of TPC was calculated using Eq. (1).

$$
\text { Concentration of TPC }\left(\frac{\mathrm{g} \mathrm{GAE}}{\mathrm{g} \text { extract }}\right)=\frac{C_{t} V_{t}}{W_{1}} \times 10^{-6}
$$

where $C_{t}$ is the concentration of gallic acid in sample extract $(\mu \mathrm{g} / \mathrm{ml}), V_{t}$ is the total volume of the sample extract $(\mathrm{ml}), W_{l}$ is the dry weight of extract $(\mathrm{g})$.

\subsection{Selection of Best Drying Temperature and Single Factor Experiments}

The best drying temperature of red dates among four different drying temperatures $(50,60$, 70 and $80^{\circ} \mathrm{C}$ ) was determined. The drying temperature that gave the highest crude extract and TPC yield was selected as the optimum drying temperature.

Single factor experiments were used to study the four parameters (liquid-solid ratio, ultrasonic power, extraction temperature and extraction time) individually and determine the optimum range of four parameters for RSM. Crude extract yield and TPC yield of red 
dates were obtained by following the experimental design which was created by varying one factor and others were kept at their midpoint.

\subsection{Optimisation of Extraction Conditions}

Box-Behken Design (BBD) of response surface methodology was used to optimise extraction conditions based on the optimum ranges determined from single factor experiments. The experiments were carried out by referring to the Design of Experiment (DOE) of BBD which was created using Design Expert software 7.0. The crude extract yield and TPC yield of TPC were determined by following the DOE created. The experiments were repeated for three times. Their average values were used to compare to determine the optimum combination of each parameter. The extraction conditions that give the highest results are chosen as the optimum extraction conditions. Besides that, the validations of optimum extraction conditions were achieved as the difference between the crude extract and TPC yield based on the optimum extraction conditions and the calculated results from the two equations provided from RSM were less than $10 \%$.

\subsection{Mathematical Modeling of Extraction Kinetic Model for Red Dates}

Three widely used extraction kinetic models, Peleg's model, Page's model and Ponomaryov's model were used to describe the process of extraction of TPC from red dates mathematically. The equation of Peleg's model, Page's model and Ponomaryov's model were showed in Eq. (2), (3) and (4) respectively. The results of TPC yield under optimum extraction conditions were fitted to the three extraction kinetic models respectively. The constants' values of each models and the coefficient value of $R^{2}$ and RMSE were determined using Matlab Curve Fitting Tool 2017. Based on the values of $R^{2}$ and RMSE obtained, the best fitted extraction kinetic model to the experiment was chosen. Furthermore, the results of TPC yield of three samples at different time were substituted into the best fitted extraction kinetic models. The validation of the best kinetic model was achieved as the difference of TPC yield calculated using the best fitted model and experimental value was less than $10 \%$.

Peleg's model: $C(t)=\mathrm{C}_{0}+\frac{t}{\mathrm{~K}_{1}+\mathrm{K}_{2} t}$

Page's model: $C(t)=e^{-\mathrm{k} t^{\mathrm{n}}}$

(3)

Ponomaryov's model: $1-\frac{c_{t}}{C_{e}}=\mathrm{b}+\mathrm{k}_{3} t$

where $C(t)$ is the concentration of TPC at time $t\left(\mathrm{mg} / \mathrm{g}_{\text {powder }}\right), C_{0}$ is the initial concentration of TPC ( $\mathrm{mg} / \mathrm{g}_{\text {powder }}$ ), $\mathrm{K}_{1}$ is Peleg's rate constant ( $\mathrm{min} \mathrm{g}_{\text {powder }} / \mathrm{mg}$ ), $\mathrm{K}_{2}$ is Peleg's capacity constant $\left(\mathrm{g}_{\text {powder }} / \mathrm{mg}\right), \mathrm{k}$ and $\mathrm{n}$ are Page's constant, $C_{e}$ is the equilibrium concentration of TPC in the plants $\left(\mathrm{mg} / \mathrm{g}_{\text {powder }}\right), \mathrm{b}$ is washing coefficient and $\mathrm{k}_{3}$ is slow extraction coefficient $\left(\mathrm{min}^{-1}\right)$. 


\section{Results and Discussions}

Based on the methodology described, discussions of results are separated into four sessions, which are determination of the optimum drying temperature, analysis of single factor experiments, analysis of response surface methodology and fitting the extraction kinetic models of red dates. The data was expressed as the average of three replicates \pm standard deviation.

\subsection{Determination of the Optimum Drying Temperature}

Red dates were dried under four different drying temperatures, which were 50, 60, 70 and $80^{\circ} \mathrm{C}$. The effects of drying temperature on crude extract and TPC yield of red dates were listed in Table 1. Based on Table 1, the crude extract and TPC yield of red dates increased with higher drying temperature up to $60^{\circ} \mathrm{C}$. The heating affects the bioavailability of total phenolic compounds [9]. The heat energy provided during drying process may break the connections between phenolic compounds and the fibre of red dates which is insoluble. Hence, the releasing of phenolic compounds throughout drying process has showed that the bioavailability of total phenolic compounds is increased by heating. Thus, the crude extract and TPC yield increased together with high drying temperature up to $60^{\circ} \mathrm{C}$.

However, at drying temperature of 70 and $80^{\circ} \mathrm{C}$, the crude extract and TPC yield of red dates started to decrease. The possible reason may be the thermal degradation of total phenolic compounds started from high drying temperature $70^{\circ} \mathrm{C}$ [10]. Similar to the results of previous findings, in this research, the optimum drying temperature was $60^{\circ} \mathrm{C}$ as the highest crude extract and TPC yield were obtained under drying temperature of $60^{\circ} \mathrm{C}$ [11].

Table 1. Effects of drying temperature on crude extract and TPC yield

\begin{tabular}{ccc}
\hline Temperature $\left({ }^{\circ} \mathrm{C}\right)$ & Crude extract yield $(\mathrm{g})$ & TPC yield $(\mathrm{g} \mathrm{GAE} / \mathrm{g}$ extract) \\
\hline 50 & $4.44 \pm 0.067$ & $0.022 \pm 0.00006$ \\
60 & $4.56 \pm 0.089$ & $0.023 \pm 0.00009$ \\
70 & $4.41 \pm 0.022$ & $0.022 \pm 0.00004$ \\
80 & $4.37 \pm 0.038$ & $0.021 \pm 0.00001$ \\
\hline
\end{tabular}

\subsection{Analysis of Single Factor Experiments}

Single factor experiments were conducted to determine the optimum range of each factor for RSM. The four factors involved were liquid-solid ratio, ultrasonic power, extraction temperature and extraction time. The effects of each factor on crude extract and TPC yield were further discussed in section 3.3.1 to 3.3.4.

\subsubsection{Effect of Liquid-Solid Ratio on Crude Extract and TPC Yield}

Based on Fig. 1, the concentration of TPC increased together with liquid-solid ratio. The concentration of TPC increased from $0.005 \pm 0.0001$ to $0.0277 \pm 0.0007 \mathrm{~g}$ GAE $/ \mathrm{g}$ extract and the crude extract yield increased from $1.032 \pm 0.0009$ to $1.905 \pm 0.053 \mathrm{~g}$ when the liquid-solid ratio increased from 10 to $30 \mathrm{ml} / \mathrm{g}$. The two graphs are having similar trend. This was because more solutes can be dissolved into solvent as the volume of solvent was larger and the contact area of solute and solvent increased [5]. At the same time, as the contact area of solute and solvent increased, the rate of mass transfer of total phenolic compounds from cell into solvent increased, thus resulting higher TPC yield. Hence, the optimum range of 
liquid-solid ratio for RSM was 10 to $30 \mathrm{ml} / \mathrm{g}$ as they gave the three highest concentration of TPC.

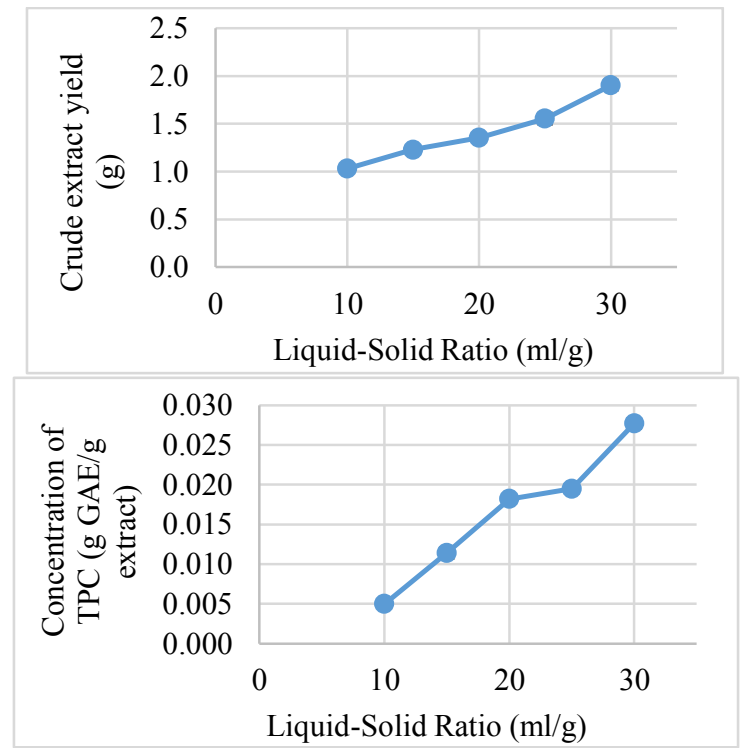

1a.

$1 b$.

Fig. 1. Effects of liquid-solid ratio on crude extract yield (1a) and TPC yield (1b).

\subsubsection{Effect of Ultrasonic Power on Crude Extract and TPC Yield}

Ultrasonic power is another factor that affects TPC and crude extract yield. Based on Fig. 2, the TPC and crude extract yield were having the similar trend. The concentration of TPC increased from $0.0132 \pm 0.0001$ to $0.0198 \pm 0.00004 \mathrm{~g} \mathrm{GAE} / \mathrm{g}$ extract and the crude extract yield increased from $1.385 \pm 0.023$ to $1.889 \pm 0.0429 \mathrm{~g}$ with higher ultrasonic power up to $80 \%$. This may due to the cavitation shear stress created by ultrasound to break the cell wall of red dates increased, thus, more TPC was able to diffuse out from the cell wall into solvent [12]. As reported from previous research, TPC is having higher stability at higher ultrasonic power [13]. Thus, more TPC was found in the solvent and the crude extract was heavier after removing the solvent.

However, under ultrasonic power of $90 \%$, the concentration of TPC was slightly decreased from $0.0198 \pm 0.00004$ to $0.0197 \pm 0.0005 \mathrm{~g} \mathrm{GAE} / \mathrm{g}$ extract while the crude extract yield decreased from $1.889 \pm 0.0429$ to $1.785 \pm 0.0247 \mathrm{~g}$. The small decrement of the two responses might due to the TPC yield has become saturated as the phenolic compounds have been dissolved into the solvent. Besides that, at $100 \%$ of ultrasonic power, a large decrement of concentration can be seen in Fig. 2. The concentration of TPC decreased might due to the degradation of TPC [14]. Hence, the optimum range of ultrasonic power for RSM was 70 to $90 \%$. 


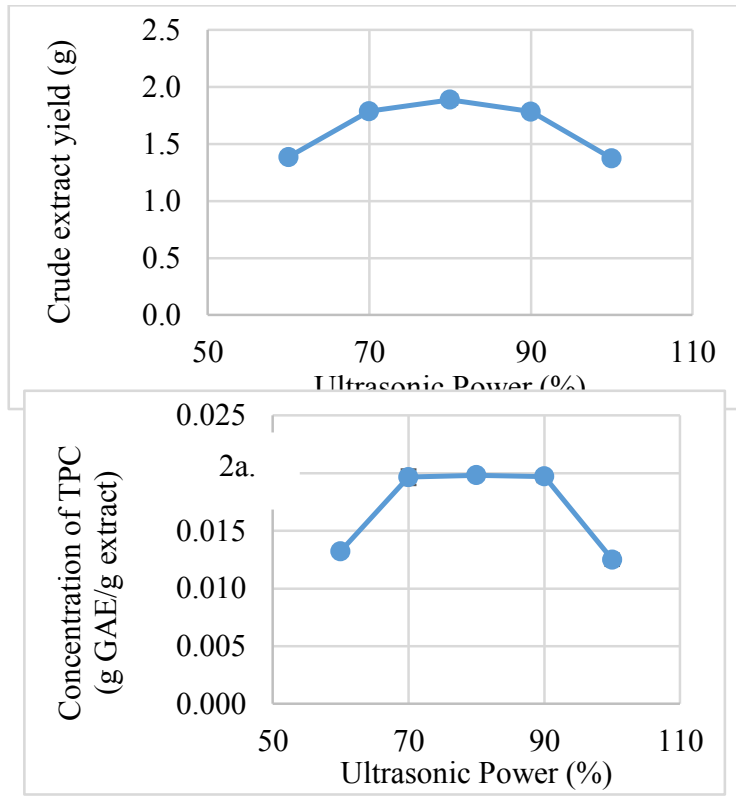

$2 b$.

Fig. 2. Effects of ultrasonic power on crude extract yield (2a) and TPC yield (2b).

\subsubsection{Effect of Extraction Temperature on Crude Extract and TPC Yield}

Based on Fig. 3, the crude extract yield increased rapidly from $1.465 \pm 0.0365$ to $1.805 \pm 0.0337 \mathrm{~g}$ and the concentration of TPC increased from $0.0138 \pm 0.0003$ to $0.0232 \pm 0.0003 \mathrm{~g} \mathrm{GAE} / \mathrm{g}$ extract as the extraction temperature was getting higher up to $60^{\circ} \mathrm{C}$. The positive effects of extraction temperature on the responses could be due to the molecules gained the energy provided by heating up the extract in the ultrasonic bath. The molecules vibrated violently when they gained the energy and broke the connections between the cell wall and TPC. Thus, TPC was able to diffuse into the solvent more easily. TPC is also readily stable under higher extraction temperature up to $60^{\circ} \mathrm{C}$ [15]. Apart from that, the solubility of molecules in red dates increased together with extraction temperature [16].

From Fig. 3, the crude extract yield and concentration of TPC dropped from $1.805 \pm 0.0337$ to $1.775 \pm 0.0266 \mathrm{~g}$ and $0.0232 \pm 0.0004$ to $0.0198 \pm 0.0001 \mathrm{~g} \mathrm{GAE} / \mathrm{g}$ extract respectively when the extraction temperature increased to $70^{\circ} \mathrm{C}$. It could be due to the decreasing of cavitation effect by ultrasonic with the increasing of extraction temperature. It caused lesser cavitation bubbles to collapse at the surface of red dates and thus, lesser TPC was extracted. Furthermore, TPC was proved to be thermo-sensitive and they underwent degradation at temperatures beyond $60^{\circ} \mathrm{C}$ [5]. Thus, the optimum range of extraction temperature for $\mathrm{RSM}$ was 50 to $70^{\circ} \mathrm{C}$. 


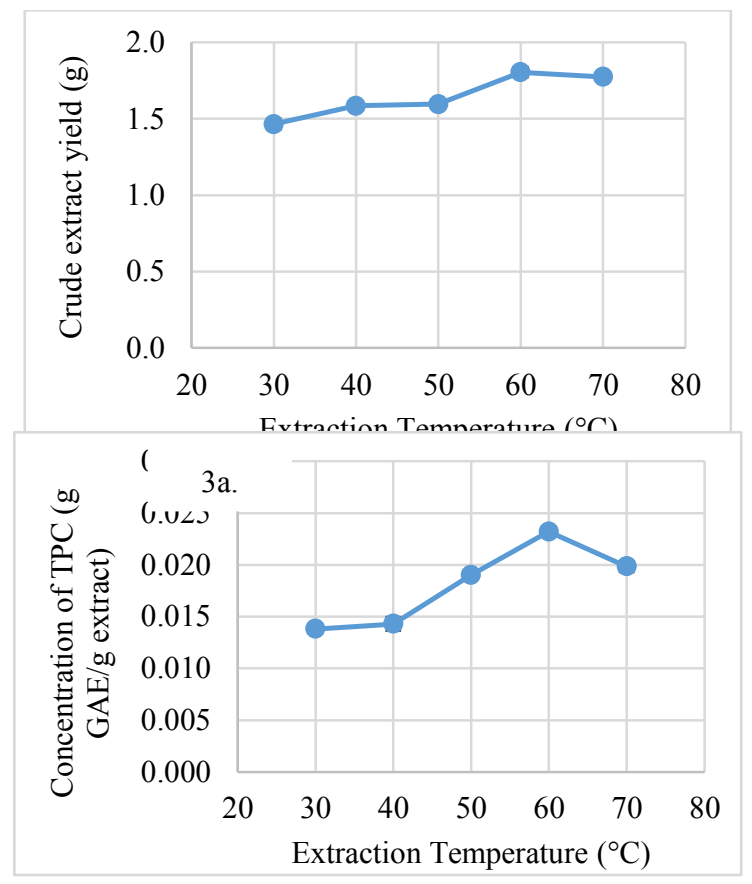

Fig. 3. Effects of extraction temp. on crude extract yield (3a) and TPC yield (3b).

\subsubsection{Effect of Extraction Time on Crude Extract and TPC Yield}

Based on Fig. 4, it can be seen that the concentration of TPC increased from $0.0211 \pm 0.0004$ to $0.0225 \pm 0.0002 \mathrm{~g} \mathrm{GAE} / \mathrm{g}$ extract at the beginning but started to decrease from $0.0225 \pm 0.0002$ to $0.0219 \pm 0.0001 \mathrm{~g} \mathrm{GAE} / \mathrm{g}$ extract when extraction time exceeded $50 \mathrm{~min}$. The crude extract yield increased from $1.695 \pm 0.0365$ to $2.007 \pm 0.0744 \mathrm{~g}$ for extraction time below $50 \mathrm{~min}$ and decreased from $2.007 \pm 0.0744$ to $1.953 \pm 0.0126 \mathrm{~g}$ for extraction time more than $50 \mathrm{~min}$.

At extraction time of $40 \mathrm{~min}$, the TPC and crude extract yield and were lower because there wasn't sufficient time for the extraction process to reach equilibrium. The rate of mass transfer of total phenolic compounds from red dates into solvent increased significantly with extraction time until $50 \mathrm{~min}$. The concentration of TPC has reached equilibrium state at extraction time of $50 \mathrm{~min}$ as it gave the highest TPC yield. For extraction time longer than $50 \mathrm{~min}$, the TPC yield decreased rapidly. It could be due to the total phenolic compounds were not stable and they started to decompose [17]. Another reason might be more impurities were extracted from red dates by cavitation effect and affected the purity of TPC. Hence, the optimum range of extraction time for RSM was 40 to $60 \mathrm{~min}$. 


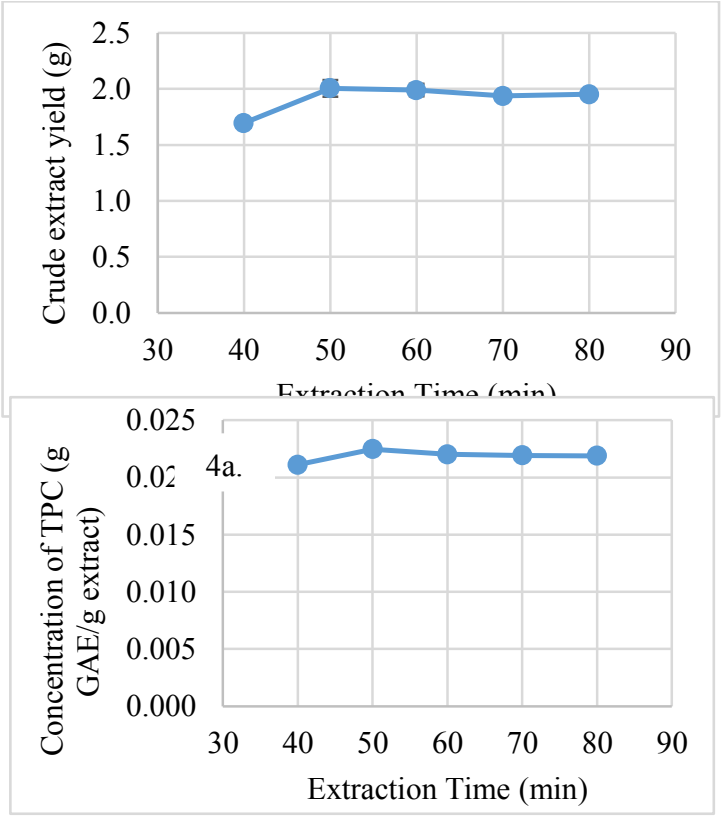

4b.

Fig. 4. Effects of extraction time on crude extract yield (4a) and TPC yield (4b).

\subsection{Analysis of Response Surface Methodology}

Based on the results obtained from single factor experiments, the range of liquid-solid ratio (A), ultrasonic power (B), extraction temperature (C) and extraction time (D) were 20$30 \mathrm{ml} / \mathrm{g}, 70-90 \%, 50-70^{\circ} \mathrm{C}$ and $40-60 \mathrm{~min}$ respectively. The range of parameters were then used to create design of experiments using Design Expert software 7.0 and the experimental results were listed in Table 2. The results were expressed in the average of three runs \pm standard deviation. 
Table 2. Experimental crude extract and TPC yield for RSM

\begin{tabular}{|c|c|c|c|c|c|c|}
\hline Run & $\mathrm{A}$ & B & $\mathrm{C}$ & $\mathrm{D}$ & Crude extract yield (g) & TPC yield (g GAE/g extract) \\
\hline 1 & 25 & 70 & 50 & 50 & $2.045 \pm 0.032$ & $0.0224 \pm 0.0002$ \\
\hline 2 & 20 & 80 & 70 & 50 & $1.755 \pm 0.014$ & $0.0195 \pm 0.0002$ \\
\hline 3 & 20 & 80 & 60 & 60 & $1.855 \pm 0.011$ & $0.0298 \pm 0.0006$ \\
\hline 4 & 25 & 70 & 70 & 50 & $2.175 \pm 0.074$ & $0.0245 \pm 0.0001$ \\
\hline 5 & 30 & 90 & 60 & 50 & $2.025 \pm 0.051$ & $0.0302 \pm 0.0008$ \\
\hline 6 & 20 & 80 & 50 & 50 & $1.315 \pm 0.020$ & $0.0265 \pm 0.0002$ \\
\hline 7 & 25 & 80 & 60 & 50 & $1.875 \pm 0.024$ & $0.0285 \pm 0.0001$ \\
\hline 8 & 30 & 80 & 70 & 50 & $2.065 \pm 0.083$ & $0.0187 \pm 0.0001$ \\
\hline 9 & 25 & 70 & 60 & 40 & $1.715 \pm 0.021$ & $0.0269 \pm 0.0006$ \\
\hline 10 & 30 & 80 & 60 & 60 & $2.175 \pm 0.022$ & $0.0298 \pm 0.0009$ \\
\hline 11 & 25 & 90 & 60 & 40 & $1.625 \pm 0.008$ & $0.0273 \pm 0.0006$ \\
\hline 12 & 25 & 80 & 60 & 50 & $1.945 \pm 0.017$ & $0.0278 \pm 0.0003$ \\
\hline 13 & 30 & 80 & 60 & 40 & $1.865 \pm 0.026$ & $0.0272 \pm 0.0003$ \\
\hline 14 & 25 & 90 & 50 & 50 & $1.545 \pm 0.009$ & $0.0258 \pm 0.0004$ \\
\hline 15 & 25 & 80 & 70 & 60 & $1.785 \pm 0.013$ & $0.0155 \pm 0.0003$ \\
\hline 16 & 20 & 80 & 60 & 40 & $1.585 \pm 0.016$ & $0.0269 \pm 0.0002$ \\
\hline 17 & 30 & 80 & 50 & 50 & $1.745 \pm 0.007$ & $0.027 \pm 0.0007$ \\
\hline 18 & 30 & 70 & 60 & 50 & $2.065 \pm 0.002$ & $0.0299 \pm 0.0008$ \\
\hline 19 & 25 & 90 & 70 & 50 & $2.045 \pm 0.044$ & $0.0165 \pm 0.0004$ \\
\hline 20 & 20 & 70 & 60 & 50 & $1.635 \pm 0.059$ & $0.0281 \pm 0.0004$ \\
\hline 21 & 25 & 80 & 60 & 50 & $2.075 \pm 0.006$ & $0.0277 \pm 0.0006$ \\
\hline 22 & 25 & 90 & 60 & 60 & $1.875 \pm 0.033$ & $0.032 \pm 0.0001$ \\
\hline 23 & 25 & 70 & 60 & 60 & $1.845 \pm 0.041$ & $0.0317 \pm 0.0001$ \\
\hline 24 & 20 & 90 & 60 & 50 & $1.855 \pm 0.005$ & $0.0244 \pm 0.0001$ \\
\hline 25 & 25 & 80 & 60 & 50 & $2.075 \pm 0.052$ & $0.0286 \pm 0.0003$ \\
\hline 26 & 25 & 80 & 70 & 40 & $2.015 \pm 0.093$ & $0.0184 \pm 0.0006$ \\
\hline 27 & 25 & 80 & 50 & 60 & $1.715 \pm 0.021$ & $0.0259 \pm 0.0002$ \\
\hline 28 & 25 & 80 & 50 & 40 & $0.845 \pm 0.015$ & $0.0194 \pm 0.0003$ \\
\hline
\end{tabular}

Based on Table 2, the range of crude extract yield was $0.845-2.175 \mathrm{~g}$, TPC yield was 0.0165-0.032 g GAE/g extract. However, the experiment with highest TPC yield did not give the highest crude extract yield. Thus, for this research, optimising TPC yield of red dates was the main objective. The optimised conditions determined were $30 \mathrm{ml} / \mathrm{g}$ of liquidsolid ratio, $70 \%$ of ultrasonic power, $60^{\circ} \mathrm{C}$ of extraction temperature and $60 \mathrm{~min}$ of extraction time. The validation was achieved as the difference between experimental and predicted TPC yield was $9.45 \%$ which was less than $10 \%$.

\subsubsection{ANOVA for Crude Extract Yield}

ANOVA is a statistical method to analyse the significance of parameters. The parameter is considered significant with P-value less than 0.05. Based on Table 3, liquid-solid ratio (A), 
extraction temperature (C), extraction time (D) and the interaction of extraction temperature and time (CD) affected the crude extract yield significantly. Ultrasonic power (B) and all the interactions of the four parameters were not significant due to their large P-value. Furthermore, the quadratic model can be used to explain the responses of crude extract yield due to its low $\mathrm{p}$-value $0.0029(\mathrm{p}<0.05)$. In addition, the $\mathrm{p}$-value of lack of fit $(\mathrm{P}=$ 0.1939) indicated the lack of fit for this model was not significant. In other words, the quadratic model was highly fitted to the experimental data of crude extract yield. 
Table 3. ANOVA for crude extract yield

\begin{tabular}{cccccc}
\hline Source & Sum of squares & $\mathrm{df}$ & Mean square & F value & P-value \\
\hline Model & 1.82 & 14 & 0.13 & 5.08 & 0.0029 \\
$\mathrm{~A}$ & 0.31 & 1 & 0.31 & 12.27 & 0.0039 \\
$\mathrm{~B}$ & 0.022 & 1 & 0.022 & 0.85 & 0.3739 \\
$\mathrm{C}$ & 0.58 & 1 & 0.58 & 22.55 & 0.0004 \\
$\mathrm{D}$ & 0.21 & 1 & 0.21 & 8.35 & 0.0127 \\
$\mathrm{AB}$ & 0.017 & 1 & 0.017 & 0.66 & 0.4308 \\
$\mathrm{AC}$ & 0.0036 & 1 & 0.0036 & 0.14 & 0.7135 \\
$\mathrm{AD}$ & 0.0004 & 1 & 0.0004 & 0.016 & 0.9024 \\
$\mathrm{BC}$ & 0.034 & 1 & 0.034 & 1.34 & 0.2680 \\
$\mathrm{BD}$ & 0.0036 & 1 & 0.0036 & 0.14 & 0.7135 \\
$\mathrm{CD}$ & 0.30 & 1 & 0.30 & 11.84 & 0.0044 \\
$\mathrm{~A}^{2}$ & 0.017 & 1 & 0.017 & 0.65 & 0.4356 \\
$\mathrm{~B}^{2}$ & 0.0007594 & 1 & 0.0007594 & 0.030 & 0.8658 \\
$\mathrm{C}^{2}$ & 0.16 & 1 & 0.16 & 6.29 & 0.0261 \\
$\mathrm{D}^{2}$ & 0.20 & 1 & 0.20 & 7.82 & 0.0151 \\
Residual & 0.33 & 13 & 0.026 & & \\
Lack of Fit & 0.30 & 10 & 0.03 & 3.06 & 0.1939 \\
Pure Error & 0.030 & 3 & 0.00982 & & \\
Cor Total & 2.15 & 27 & & & \\
\hline
\end{tabular}

The relationships of linear, interaction and quadratic effects of each parameters were expressed in a quadratic equation, Eq.(5). Eq.(5) can also be used to predict the crude extract yield under different extraction conditions.

$$
\begin{gathered}
\text { Crude extract yield }= \\
+17.3675+0.26733 A-0.0603 B+0.29692 C \\
+0.33183 D-0.0013 A B-0.0006 A C+0.0002 A D \\
+0.000925 B C+0.00003 B D-0.00275 C D-0.0021 A^{2} \\
+0.00001125 B^{2}-0.0016375 C^{2}-0.001825 D^{2}
\end{gathered}
$$

To simplify the quadratic equation created using Design Expert Software Version 7.0, the non-significant $(\mathrm{P}>0.05)$ factors and interactions were removed. The simplified equation, Eq (6) was showed below:

$$
\begin{aligned}
& \quad \text { Crude extract yield }= \\
& -19.0265+0.0323 A+0.3460 C \\
& +0.3526 D-0.00275 C D-0.001555 C^{2}-0.001743 D^{2}
\end{aligned}
$$

The correlation coefficient $\left(\mathrm{R}^{2}\right)$ of Eq.(6) was 0.7987 while the $\mathrm{R}^{2}$ of Eq.(5) was 0.8455 . The $\mathrm{R}^{2}$ of Eq.(5) was higher than Eq.(6). It can be said that the predicted responses value from Eq.(5) were closer to the fitted regression line compared to Eq.(6). Thus, Eq.(5) was suitable to be used to predict crude extract yield instead of Eq.(6).

The parameters with positive coefficient from Eq.(5) gave positive effects to crude extract yield while the parameters with negative coefficient gave negative effects to crude extract yield. Based on Eq.(5), the coefficients of liquid-solid ratio, extraction temperature and time were positive. Thus, the crude extract yield increases together with liquid-solid ratio, extraction temperature and time. 


\subsubsection{ANOVA for TPC Yield}

Based on Table 4, extraction temperature (C), extraction time (D), the interaction of ultrasonic power and extraction temperature $(\mathrm{BC})$, ultrasonic power and extraction time (BD) and quadratic term of extraction temperature $\left(\mathrm{C}^{2}\right)$ were significant in affecting TPC yield due to their low p-values $(\mathrm{P}<0.05)$. The other parameters and interactions of the four parameters were not significant as their p-values were more than 0.05 . In addition, the pvalue of quadratic model for TPC yield was 0.0016 . The experimental results were highly fitted to the quadratic model due to its low p-value. The lack of fit of the model was also calculated using Design Expert Software Version 7.0 to analyse the error in the model. The value of lack of fit of this quadratic model was 0.5342 , which was less than 0.05 . It can be said that the quadratic model was very close to the responses of experimental TPC yield. 
Table 4. ANOVA for TPC yield

\begin{tabular}{cccccc}
\hline Source & Sum of squares & $\mathrm{df}$ & Mean square & F value & p-value \\
\hline Model & 0.0004675 & 14 & 0.00003339 & 5.78 & 0.0016 \\
A & 0.000003715 & 1 & 0.000003715 & 0.64 & 0.4370 \\
B & 0.000003203 & 1 & 0.000003203 & 0.55 & 0.4697 \\
C & 0.00007489 & 1 & 0.00007489 & 12.96 & 0.0032 \\
D & 0.00003571 & 1 & 0.00003571 & 6.18 & 0.0273 \\
AB & 0.000004 & 1 & 0.000004 & 0.69 & 0.4204 \\
AC & $8.327 \times 10^{-8}$ & 1 & $8.327 \times 10^{-8}$ & 0.014 & 0.9063 \\
AD & 0.000001823 & 1 & 0.000001823 & 0.32 & 0.5839 \\
BC & 0.00002704 & 1 & 0.00002704 & 4.68 & 0.0497 \\
BD & $2.5 \times 10^{-9}$ & 1 & $2.5 \times 10^{-9}$ & 0.0006891 & 0.9795 \\
CD & 0.00000484 & 1 & 0.00000484 & 0.84 & 0.3767 \\
A & 0.000007066 & 1 & 0.000007066 & 1.22 & 0.2888 \\
B & 0.000006551 & 1 & 0.000006551 & 1.13 & 0.3063 \\
C $^{2}$ & 0.0002364 & 1 & 0.0002364 & 40.92 & $<0.0001$ \\
$\mathrm{D}^{2}$ & $2.226 \times 10^{-7}$ & 1 & $2.226 \times 10^{-7}$ & 0.039 & 0.8474 \\
Residual & 0.0000751 & 13 & 0.00000577 & & \\
Lack of Fit & 0.00005885 & 10 & 0.000005885 & 1.09 & 0.5342 \\
Pure Error & 0.00001625 & 3 & 0.000005417 & & \\
Cor Total & 0.0005426 & 27 & & & \\
\hline A quadratic & equation & & & \\
\hline
\end{tabular}

A quadratic equation, Eq.(7) was formed to predict the TPC yield under different conditions. The coefficients of extraction temperature and time were positive while the coefficient of liquid-solid ratio ultrasonic power were negative. Hence, the TPC yield increases if lower liquid-solid ratio, lower ultrasonic power, extraction temperature and time are used.

$$
\begin{aligned}
& -0.19853-0.00451 A-0.000663 B+0.00984 C \\
\text { TPC yield }= & +0.000688 D+2 \times 10^{-5} A B-2.886 \times 10^{-6} A C+1.35 \times 10^{-5} A D \\
& -2.6 \times 10^{-5} B C-2.5 \times 10^{-7} B D-1.1 \times 10^{-5} C D \\
& +4.34 \times 10^{-5} A^{2}+1.05 \times 10^{-5} B^{2}-6.27 \times 10^{-5} C^{2}-1.93 \times 10^{-6} D^{2}
\end{aligned}
$$

By removing the non-significant factors and interaction, Eq.(7) was simplified to Eq.(8).

$$
\text { TPC yield }=0.028-0.002498 C+0.001725 D-0.0026 B C-0.0066 C^{2}
$$

The correlation coefficients $\left(\mathrm{R}^{2}\right)$ of Eq.(7) and Eq.(8) were 0.9173 and 0.8042 respectively. The $\mathrm{R}^{2}$ of Eq.(7) dropped from 0.9173 to 0.8042 after simplifying. By considering more factors and interactions, the predicted values determined using Eq.(7) were closer to the regression line. Thus, Eq. (7) was highly suitable to be used to predict the TPC yield due to its high $\mathrm{R}^{2}$ value, 0.9173 .

\subsection{Fitting the Extraction Kinetic Models of Red Dates}

In this research, the experimental data was compared with the predicted data using three kinetic models (Peleg's model, Page's model, Ponomaryov's model). Fig. 5-7 show the comparison graphs of experimental data and the three mentioned kinetic models respectively. The results are showed in Table 5. 


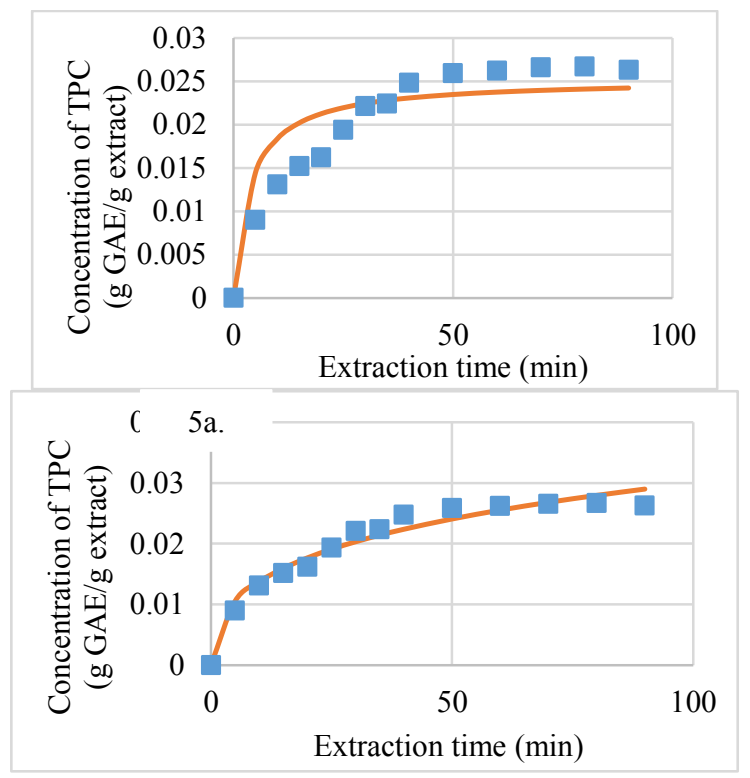

$5 b$.

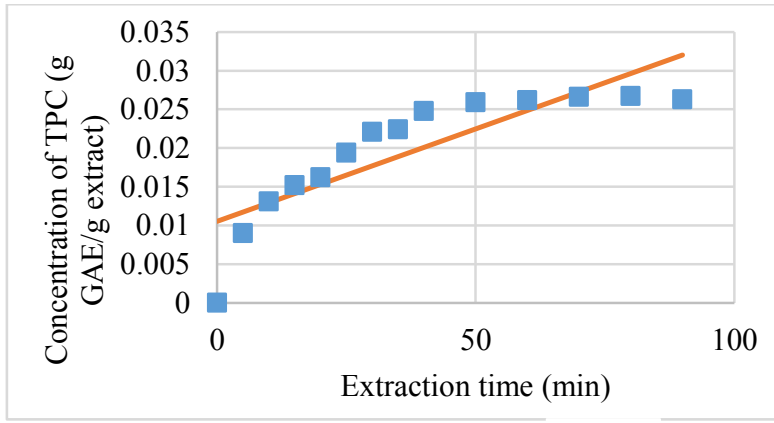

$5 c$.

Fig. 5. Fittings of Peleg's model (5a), Page's (5b) and Ponomaryov's model (5c).

Table 5. Root mean square error (RMSE), coefficient of determination $\left(\mathrm{R}^{2}\right)$ and models'constants of kinetic models

\begin{tabular}{cccc}
\hline Model & Model's constants & $R^{2}$ & RMSE \\
\hline Peleg's model & $K_{l}=148.1, K_{2}=39.65$ & 0.824 & 0.003506 \\
Page's model & $k=5.241, n=-0.08715$ & 0.9663 & 0.001534 \\
Ponomaryov's model & $k_{3}=0.02623, b=2.157, C_{e}=-0.009102$ & 0.716 & 0.004652 \\
\hline
\end{tabular}

The calculated models' constants were showed in Table 5. As shown in Fig. 5, the line of predicted data calculated using Page's model passed through the most experimental data points compared to the rest of kinetic models. In addition, $\mathrm{R}^{2}$ and RMSE of each model were calculated using Matlab Curve Fitting Tool 2017. The experimental data is highly fitted to the kinetic model if the value of $\mathrm{R}^{2}$ is close to unity while RMSE is close to zero. Based on Table 5, the model with the highest $\mathrm{R}^{2}, 0.9663$ and lowest RMSE, 0.001534 was Page's model. Therefore, Page's model was the most suitable to describe the extraction process of TPC from red dates among the mentioned models. The fittings of the mentioned models were in order of: Page's model $>$ Peleg's model $>$ Ponomaryov model. 
Validation of extraction kinetic model was carried out to ensure that the most suitable kinetic model (Page's model) to describe the extraction process of TPC from red dates is reliable. The experimental results of TPC yield under optimum extractions at $45 \mathrm{~min}, 65$ min and 85 min were compared with the predicted data calculated using Page's model, Eq. (9). The differences of experimental and predicted data are showed in Table 6.

$$
\text { Page's model: } C(t)=e^{-\left(5.241 \times t^{-0.08715}\right)}
$$

Table 6. Difference of experimental and predicted TPC yield

\begin{tabular}{cccc}
\hline \hline \multirow{2}{*}{ Extraction time (min) } & \multicolumn{2}{c}{ TPC yield (g GAE/g extract) } & \multirow{2}{*}{ Difference (\%) } \\
\cline { 2 - 3 } & Experimental & Predicted & \\
\hline 45 & $0.0253 \pm 0.0002$ & 0.0233 & 8.20 \\
65 & $0.0250 \pm 0.0004$ & 0.0262 & 4.83 \\
85 & $0.0259 \pm 0.0002$ & 0.0285 & 9.97 \\
\hline \hline
\end{tabular}

Based on Table 6 , the differences between experimental and predicted TPC yield at extraction time 45,65 and $85 \mathrm{~min}$ were $8.2 \%, 4.83 \%$ and $9.97 \%$ respectively. The validation of extraction kinetic model was achieved as the differences between experimental and predicted TPC yield were less than 10\%. Therefore, Page's model was most reliable and most suitable to be used to predict the TPC yield of red dates at different extraction times.

\section{Conclusion}

In this research, the optimised conditions to extract total phenolic compounds from red dates were determined using response surface methodology. The optimum value for liquidsolid ratio, ultrasonic power, extraction temperature and extraction time were $30 \mathrm{ml} / \mathrm{g}, 70 \%$, $60^{\circ} \mathrm{C}$ and $60 \mathrm{~min}$ respectively. Besides that, among three extraction kinetic models, Page's model is the most suitable to be used to describe the extraction kinetics of total phenolic compounds of red dates due to its coefficient of determination $\left(R^{2}\right)$ was the closest to unity, 0.9663 while its root mean square error (RMSE) was the closest to zero, 0.001534 .

The author would like to express her gratitude to her supervisor, Dr. Chua Bee Lin for her support, guidance and encouragement. The author also would like to give appreciation to lab assistants from Taylor's University for their advices. The authors would like to acknowledge Taylor's University Lakeside for providing financial support under TRGS/MFS/1/2016/SOE/004.

\section{References}

1. Valdivia-Correa, B., Gómez-Gutiérrez, C., Uribe, M. \& Méndez-Sánchez, N. Herbal medicine in Mexico: A cause of hepatotoxicity. A critical review. Int. J. Mol. Sci. 17, 48-49 (2016).

2. Norhasidah S, Z.Farahniza, A.G. Maaruf, E.U. Engku Hanisah, B. A. S. Antioxidative properties of edible bird's nest mincroparticulates incorporated into red dates drink. 4-6 (2014).

3. Yao, S. Past, Present, and Future of Jujubes - Chinese Dates in the United States. HortScience 48, 672-680 (2013).

4. Al Harthi, S. S., Mavazhe, A., Al Mahroqi, H. \& Khan, S. A. Quantification of phenolic compounds, evaluation of physicochemical properties and antioxidant activity of four 
date (Phoenix dactylifera L.) varieties of Oman. J. Taibah Univ. Med. Sci. 10, 346-352 (2015).

5. Yang, Y. C., Wei, M. C., Huang, T. C., Lee, S. Z. \& Lin, S. S. Comparison of modified ultrasound-assisted and traditional extraction methods for the extraction of baicalin and baicalein from Radix Scutellariae. Ind. Crops Prod. 45, 182-190 (2013).

6. Dailey, A. \& Vuong, Q. Optimum Conditions for Microwave Assisted Extraction for Recovery of Phenolic Compounds and Antioxidant Capacity from Macadamia (Macadamia tetraphylla) Skin Waste Using Water. Processes 4, 2 (2015).

7. Jokic, S. et al. Modelling of the process of solid-liquid extraction of total polyphenols from soybeans. Czech J. Food Sci. 28, 206-212 (2010).

8. Anuar, N., Mohd Adnan, A. F., Saat, N., Aziz, N. \& Mat Taha, R. Optimization of extraction parameters by using response surface methodology, purification, and identification of anthocyanin pigments in melastoma malabathricum fruit. Sci. World J. 2013, (2013).

9. Kim, H. S. \& Chin, K. B. Effects of Drying Temperature on Antioxidant Activities of Tomato Powder and Storage Stability of Pork Patties. Korean J. Food Sci. Anim. Resour. 36, 51-60 (2016).

10. Larrauri, J. A., Rupérez, P. \& Saura-Calixto, F. Effect of drying temperature on the stability of polyphenols and antioxidant activity of red grape pomace peels. J. Agric. Food Chem. 45, 1390-1393 (1997).

11. Planinić, M. Influence of Temperature and Drying Time on Extraction Yield of Phenolic Compounds from Grape Pomace Variety 'Portogizac'. Chem. Biochem. Eng. Q. 29, 343-350 (2015).

12. Karki, B. Use of high-power ultrasound during soy protein production and study of its effect on functional properties of soy protein isolate. (2009).

13. S.Rodrigues, F. F. Advances in Fruit Processing Technologies. (Taylor \& Francis Group, 2012).

14. Ince, A. E., Şahin, S. \& Şümnü, S. G. Extraction of phenolic compounds from melissa using microwave and ultrasound. Turkish J. Agric. For. 37, 69-75 (2013).

15. Ruenroengklin, N. et al. Effects of various temperatures and $\mathrm{pH}$ values on the extraction yield of phenolics from litchi fruit pericarp tissue and the antioxidant activity of the extracted anthocyanins. Int. J. Mol. Sci. 9, 1333-1341 (2008).

16. Qu, W., Pan, Z. \& Ma, H. Extraction modeling and activities of antioxidants from pomegranate marc. J. Food Eng. 99, 16-23 (2010).

17. Ibrahim, U. K., Austin, E. A. \& Mohd Salleh, R. Effect of Drying Temperature and Time on Antioxidant and Total Phenolic Content in Garcinia mangostana Pericarp. Adv. Mater. Res. 1113, 279-284 (2015). 